\title{
Mammary blood flow and metabolic activity are linked by a feedback mechanism involving nitric oxide synthesis
}

\author{
S. R. L. Cieslar, ${ }^{\star}$ T. G. Madsen, $\nmid$ N. G. Purdie, ${ }^{\star} \ddagger{ }^{1}$ D. R. Trout, $§$ V. R. Osborne, ${ }^{\star}$ and J. P. Cant ${ }^{\star 2}$ \\ ${ }^{*}$ Department of Animal and Poultry Science, University of Guelph, Ontario N1G 2W1, Canada \\ †Department of Basic Animal and Veterinary Sciences, The Faculty of Life Sciences, Copenhagen University, DK-1870 Frederiksberg C, Denmark \\ $\ddagger$ Schools of Animal Studies and Veterinary Science, University of Queensland, St Lucia 4072, Brisbane, Australia \\ $\S$ Department of Clinical Studies, University of Guelph, Ontario N1G 2W1, Canada
}

\begin{abstract}
To test which, if any, of the major milk precursors can elicit a rapid change in the rate of mammary blood flow (MBF) and to define the time course and magnitude of such changes, 4 lactating cows were infused with glucose, amino acids, or triacylglycerol into the external iliac artery feeding one udder half while iliac plasma flow (IPF) was monitored continuously by dye dilution. Adenosine and saline were infused as positive and negative controls, respectively, and insulin was infused to characterize the response to a centrally produced anabolic hormone. To test the roles of cyclooxygenase, NO synthase and ATP-sensitive $\mathrm{K}\left(\mathrm{K}_{\mathrm{ATP}}\right)$ channels in nutrient-mediated changes in blood flow, their respective inhibitors - indomethacin, $\mathrm{N}_{\omega}$-nitro-Larginine methyl ester hydrochloride (L-NAME), and glibenclamide - were infused simultaneously with glucose. Each day, 1 infusate was given twice to each cow, over a 20 -min period each time, separated by a 20 -min washout period. In addition, each treatment protocol was administered on 2 separate days. A $73 \%$ increase in IPF during adenosine infusion showed that the mammary vasodilatory response was quadratic in time, with most changes occurring in the first $5 \mathrm{~min}$. Glucose infusion decreased IPF by $9 \%$ in a quadratic manner, most rapidly in the first $5 \mathrm{~min}$, indicating that a feedback mechanism of local blood flow control, likely through adenosine release, was operative in the mammary vasculature. Amino acid infusion increased IPF $9 \%$ in a linear manner, suggesting that mammary ATP utilization was stimulated more than ATP production. This could reflect a stimulation of protein synthesis. Triacylglycerol only tended to decrease IPF and insulin did not affect IPF. A lack of IPF response to glibenclamide indicates that $\mathrm{K}_{\mathrm{ATP}}$ channels are not involved in $\mathrm{MBF}$
\end{abstract}

\footnotetext{
Received April 25, 2013.

Accepted December 18, 2013.

${ }^{1}$ Current address: Department of Animal Science, University of Vermont, Burlington 05405.

${ }^{2}$ Corresponding author: jcant@uoguelph.ca
}

regulation. Indomethacin and L-NAME both depressed IPF. In the presence of indomethacin, glucose infusion caused a quadratic 9\% increase in IPF. Indomethacin is an inhibitor of mitochondrial function, so the glucoseinduced increase in IPF was interpreted as feedback on mammary adenosine release from an anabolic response to glucose. Because NO synthase was not inhibited during indomethacin infusion, the feedback system is postulated to act through endothelial NO synthase. In the presence of L-NAME, glucose infusion had no effect on IPF, indicating that endothelial cyclooxygenase is not involved in glucose-induced changes in MBF.

Key words: mammary blood flow, nitric oxide synthase, cyclooxygenase, glucose

\section{INTRODUCTION}

Several tissues, including skeletal muscle (Jones and Berne, 1964), kidney (Haddy et al., 1958), heart (Scott et al., 1965), and the mammary glands (Linzell, 1974), have the ability to locally regulate their own blood flow according to metabolic activity in the tissue. A combination of feedforward and feedback mechanisms has been postulated to link metabolic activity with blood flow in skeletal and cardiac muscle. In feedforward mechanisms, products of energy metabolism stimulate blood flow, and in feedback mechanisms, they inhibit blood flow. One example of a feedforward mechanism involves production of $\mathrm{CO}_{2}$ in muscle, which results in $\mathrm{H}^{+}$-mediated activation of ATP-sensitive $\mathrm{K}\left(\mathbf{K}_{\text {ATP }}\right)$ channels in smooth muscle cells surrounding capillaries, causing relaxation and vasodilation (Deussen et al., 2012), presumably to improve nutrient supply for an elevated workload. Endothelial synthesis of the vasodilator $\mathrm{NO}$ also appears to be involved in $\mathrm{CO}_{2}$-mediated hyperemia (Gurevicius et al., 1995). Another feedforward mechanism involves production of $\mathrm{H}_{2} \mathrm{O}_{2}$ during oxidative metabolism, which acts through voltage-gated $\mathrm{K}\left(\mathbf{K}_{\mathbf{V}}\right)$ channels on smooth muscle cells (Rogers et al., 2006) and cyclooxygenase (COX)-mediated prostacyclin $\left(\mathbf{P G I}_{2}\right)$ synthesis in endothelial cells (Thengchaisri and Kuo, 2003) to dilate capillaries. Adenosine is a 
feedback vasodilator that is released when intracellular ATP is low; it relaxes smooth muscle by activating $\mathrm{K}_{\text {ATP }}$ channels and endothelial NO synthase (Hein and Kuo, 1999; Deussen et al., 2012).

Adenosine, $\mathrm{NO}$ synthase, and $\mathrm{PGI}_{2}$ have all been shown to be active in the mammary vasculature of lactating ruminants (Oguro et al., 1982; Nielsen et al., 1995a; Lacasse et al., 1996; Prosser et al., 1996), leading to the proposition that the mammary gland has the ability to locally control its own blood flow and, hence, arterial nutrient supply. A corollary to this proposition is that arterial nutrient supply should, in turn, have an influence on mammary blood flow (MBF) and, indeed, infusion of $90 \mathrm{~g} / \mathrm{h}$ glucose into the external iliac artery supplying one udder half for $10 \mathrm{~h}$ reduced MBF by 16\% (Cant et al., 2002), removal of histidine from an AA infusion into the abomasum caused an increase in MBF (Bequette et al., 2000), and elevation of plasma triacylglycerol (TAG) by fat supplementation of the diet caused a reduction in MBF:milk yield ratio (Cant et al., 1993). Accordingly, Cant and McBride (1995) and Cherepanov et al. (2000) constructed mathematical models of nutrient utilization in the mammary glands in which MBF is modified locally to match energy supply with expenditure. Mechanisms by which metabolic activity influences MBF were not specified because they have not been identified. The mammary models simulate changes in MBF that commence immediately on perturbation of arterial nutrient concentrations but we are unaware of any experimental data that demonstrate short-term responses of $\mathrm{MBF}$ to nutrient supply. Cherepanov et al. (2000) point out that the response delay would encompass rate of vasodilator production, reactivity of the capillaries, and hydraulic characteristics of the microvasculature. Blood flow to several organs, including the mammary glands, increases within seconds of administration of vasodilators into the arterial supply (Oguro et al., 1982; Rådegran and Hellsten, 2000). In muscle, blood flow reaches 50\% of its maximum increase within 2 to $9 \mathrm{~s}$ of the onset of exercise (Rådegran and Saltin, 1998).

A greater understanding of the mechanisms involved in local regulation of mammary blood flow would allow predictive models to better account for variation in nutrient uptake and utilization for milk synthesis. To test which, if any, of the major milk precursors can elicit a rapid change in the rate of $\mathrm{MBF}$, and to define the time course and magnitude of such changes, lactating cows were infused with glucose, AA, or TAG into the external iliac artery feeding one udder half while blood flow was monitored by dye dilution. Adenosine and saline were infused as positive and negative controls, respectively, and insulin was infused to characterize the response to a centrally produced, anabolic hormone. To test the roles of COX, NO synthase, and $\mathrm{K}_{\mathrm{ATP}}$ channels in nutrient-mediated changes in blood flow, their respective inhibitors indomethacin, $\mathrm{N}_{\omega}$-nitro-L-arginine methyl ester hydrochloride (L-NAME), and glibenclamide were infused simultaneously with glucose.

\section{MATERIALS AND METHODS}

\section{Animals}

All animal procedures and holding facilities were approved by the Animal Care Committee of the University of Guelph. Four multiparous Holstein cows, at 580 $\pm 29.3 \mathrm{~kg}$ of BW and $54 \pm 8.9 \mathrm{DIM}( \pm$ SEM $)$ were fitted with polyurethane catheters in both left and right subcutaneous abdominal veins (milk veins) and with polyethylene catheters in both iliac arteries, introduced through the saphenous arteries as described by Maas et al. (1995). The external iliac position was confirmed by injection of Evan's Blue dye into the arterial catheters (Cant et al., 2001).

After $2 \mathrm{~d}$ of recovery in box stalls, cows were housed in tie stalls with mattresses and wood shavings. They were milked and fed a corn silage-based TMR (50.5\% DM, $17.7 \%$ CP, $32.6 \% \mathrm{NDF}, 3.6 \%$ fat, 1.74 Mcal of $\mathrm{NE}_{\mathrm{L}} / \mathrm{kg}$ on a DM basis) twice daily at 0800 and $1800 \mathrm{~h}$. Refusals were weighed at $0730 \mathrm{~h}$ daily to determine feed intake. Milk was sampled at each milking and analyzed by infrared spectroscopy for protein, fat, and lactose (AOAC International, 1996).

\section{Infusion Protocols}

Commencing on d 5 after surgery, cows were subjected twice daily to a 95-min infusion protocol into one external iliac catheter, starting at 1000 or $1400 \mathrm{~h}$. Para-aminohippuric acid (PAH; Na salt) was infused continuously at $100 \mathrm{mg} / \mathrm{min}$ throughout the entire 95 min to estimate iliac plasma flow by arteriovenous dilution. As depicted in Figures 1, 2, 3, 4, 5, and 6, a treatment solution was infused for $20 \mathrm{~min}$, commencing at 30 min of PAH infusion, and after a second baseline period, at $70 \mathrm{~min}$ of $\mathrm{PAH}$ infusion. The same treatment was infused both times. Treatments were $0.38 \mathrm{~g} / \mathrm{min}$ of $\mathrm{NaCl}, 3 \mathrm{mg} / \mathrm{min}$ of adenosine (Sigma Chemical Co., St. Louis, MO), $2.2 \mathrm{~g} / \mathrm{min}$ of glucose (Sigma Chemical Co.), $2.11 \mathrm{~g} / \mathrm{min}$ of a complete AA mix (Table 1), $0.87 \mathrm{~g} / \mathrm{min}$ of TAG (10\% Liposyn; Abbott Laboratories Ltd., Montreal, Quebec, Canada), $20 \mu \mathrm{g} / \mathrm{min}$ of insulin (Sigma Chemical Co.), $2.0 \mathrm{mg} / \mathrm{min}$ of indomethacin (Sigma Chemical Co.), $25 \mathrm{mg} / \mathrm{min}$ of L-NAME (Sigma Chemical Co.), or $2.0 \mathrm{mg} / \mathrm{min}$ of glibenclamide (Sigma Chemical Co.). Glucose and AA solutions were prepared at 220 and $211 \mathrm{~g} / \mathrm{L}$, respectively. The complete 
mix of AA (United States Biochemical, Cleveland, $\mathrm{OH}$ ) was formulated to the AA profile of milk protein (Hambraeus, 1982), assuming $80 \%$ casein and $20 \%$ whey proteins, with equimolar replacement of Gln, Asn, and Tyr by Glu, Asp, and Phe, respectively, as previously described (Purdie et al., 2008). Liposyn contains 5\% safflower oil, $5 \%$ soybean oil, $1.2 \%$ egg phosphatides, and $2.5 \%$ glycerol in water, where linoleic, oleic, palmitic, linolenic, and stearic acids account for $65.8,17.7,8.8$, 4.2 , and $3.4 \%$ of the FA, respectively. All milk precursor infusion rates were balanced to equivalent yields of ATP from oxidative metabolism, assuming $0.20 \mathrm{~mol}$ of $\mathrm{ATP} / \mathrm{g}$ of glucose, $0.21 \mathrm{~mol}$ of $\mathrm{ATP} / \mathrm{g}$ of AA, and 0.51 mol of ATP $/ \mathrm{g}$ of TAG. The $0.38 \mathrm{~g} / \mathrm{min} \mathrm{NaCl}$ infusion was equivalent in osmolality to the glucose infusion, at $1.2 \mathrm{mOsm} / \mathrm{L}$. The solutions of insulin were prepared daily for each cow from frozen aliquots $(1 \mathrm{mg}$ of insulin/mL of water containing $1 \%$ BSA and $50 \mu \mathrm{L}$ of $6 N$ $\mathrm{HCl}$ ). All solutions were filtered for sterility through $0.22-\mu \mathrm{m}$ cellulose acetate filters into autoclaved polypropylene bottles and refrigerated overnight.

Infusate bottles were weighed frequently during infusion to monitor flow rate by time-series regression. Infusion lines from $\mathrm{PAH}$ and treatment solutions were joined beyond the peristaltic pump via a Y-connector so that only one line extended to the arterial catheter. Both solutions were infused at $10 \mathrm{~mL} / \mathrm{min}$. To maintain a constant PAH infusion rate between baseline and treatment periods, a solution of $0.9 \% \mathrm{NaCl}$ was also infused at $10 \mathrm{~mL} / \mathrm{min}$ during baseline periods. Treatment periods began by switching from $0.9 \% \mathrm{NaCl}$ to treatment solutions without changing the total volume flow rate to the catheter.

Table 1. Difference between mean minimum and maximum iliac plasma flow (IPF, as a percentage of the baseline value) during 20-min infusions and $P$-values of linear and quadratic effects of time during infusion

\begin{tabular}{lrrr}
\hline & & \multicolumn{2}{c}{$P$-value } \\
\cline { 3 - 4 } Infusion & IPF & Linear & Quadratic \\
\hline Saline & -0.03 & 0.81 & 0.94 \\
Adenosine & 73.4 & $<0.01$ & $<0.01$ \\
Glucose & -8.8 & 0.10 & 0.05 \\
Amino acids & 8.6 & 0.01 & 0.30 \\
Triacylglycerol & -7.4 & 0.37 & 0.08 \\
Insulin & -0.1 & 0.45 & 0.88 \\
Indomethacin & -37.2 & $<0.01$ & $<0.01$ \\
L-NAME & -11.9 & $<0.01$ & 0.40 \\
Glibenclamide & -1.5 & 0.75 & 0.80 \\
Glucose during & & & \\
Indomethacin & 9.3 & $<0.01$ & 0.02 \\
L-NAME & -4.8 & 0.43 & 0.22 \\
Glibenclamide & 8.4 & 0.39 & 0.18 \\
\hline
\end{tabular}

${ }^{1} \mathrm{~N}_{\omega}$-nitro-L-arginine methyl ester hydrochloride.
Blood samples were collected continuously via peristaltic pump from the external iliac arterial catheter contralateral to infusion and the ipsilateral subcutaneous milk vein. Blood was collected into sealed, heparinized Vacutainers (Becton Dickinson, Franklin Lakes, NJ) on ice through platinum-cured, silicone, peristaltic pump tubing attached to respective catheters. Blood sampling started at 21 min of PAH infusion and blood collection tubing was sequentially moved to new Vacutainers at 24, 27, 52, 55, 67, 92, and 95 min of PAH infusion, and $0,1,2,3,5,10,15$, and 20 min of treatment infusion. Plasma was separated by centrifugation for 20 min at $1,500 \times g$ and $4^{\circ} \mathrm{C}$. Plasma was transferred to propylene tubes and stored at $-20^{\circ} \mathrm{C}$ until analysis was performed.

A subset of experiments was performed with glucose infusion during infusion of the blood flow inhibitors indomethacin, L-NAME, or glibenclamide. In this subset of experiments, $\mathrm{PAH}$ was infused continuously for 74 min and the inhibitor was infused from 30 to 74 min of PAH infusion. Glucose was infused between 44 and 64 min of PAH infusion. The fraction collector for blood sample collection was moved to new Vacutainers at 20, $40,43,66,68$, and 71 min of PAH infusion and at 0,1 , $2,3,5,8,13$, and 18 min of glucose infusion.

\section{Sample Analysis and Calculations}

Concentrations of $\mathrm{PAH}$ in plasma and infusates, and of glucose, TAG, and NEFA in plasma were analyzed as described by Cant et al. (2001). Plasma $\alpha$-amino-N was determined according to Evans et al. (1993). Insulin was assayed in plasma by ${ }^{125} \mathrm{I}$ radioimmunoassay (Diagnostic Products Corp., Los Angeles, CA).

Rate of plasma flow in the external iliac artery for each sampling time was calculated as the quotient of $\mathrm{PAH}$ infusion rate and venoarterial concentration difference. Because of difficulties associated with placing catheters in the external pudendal artery supplying each udder half, we chose a simpler approach to arterial catheterization in the external iliac. However, approximately $20 \%$ of external iliac plasma does not flow to the mammary glands and flows to the hind limb via the femoral artery (Bequette et al., 2001; Cant et al., 2002). External iliac plasma flow (IPF) was compared with hind leg flow in one cow fitted with a polyethylene catheter in a tarsal vein upon completion of experiments. A baseline arterial blood sample was obtained, and then $\mathrm{PAH}$ was rapidly injected into the arterial catheter, and blood was collected from the tarsal vein via syringe pump for exactly $1 \mathrm{~min}$. The procedure was repeated several times. The tip of the arterial catheter was then pulled past the deep femoral artery (through which the mammary blood flows), as confirmed by 
Evan's Blue dye injection, and the PAH injection procedure was repeated several times. Plasma flow was calculated as $[\mathrm{PAH}$ dose $(\mathrm{g}) \div \mathrm{PAH}$ venoarterial difference $(\mathrm{g} / \mathrm{L})] \div$ sample time $(\mathrm{min})$. Average plasma flow to the hind leg was $21 \%$ of IPF.

Arterial concentrations of infused metabolites on the infused side were calculated as contralateral arterial concentration $(\mathrm{m} M)+$ infusion rate $(\mathrm{mmol} / \mathrm{min}) \div$ $\mathrm{IPF}(\mathrm{L} / \mathrm{min})$.

\section{Statistical Analysis}

Each 95- or 74-min test of each treatment was conducted twice on each of 4 cows for a total of 8 replications. The 95-min tests included 9 treatments and the 74-min tests 3 treatments, for a total of 12 treatments. Infusion protocols commenced at 1000 and $1400 \mathrm{~h}$ on each of 12 consecutive days.

Changes in IPF at each sampling time in the 95-min protocol were calculated relative to the first baseline
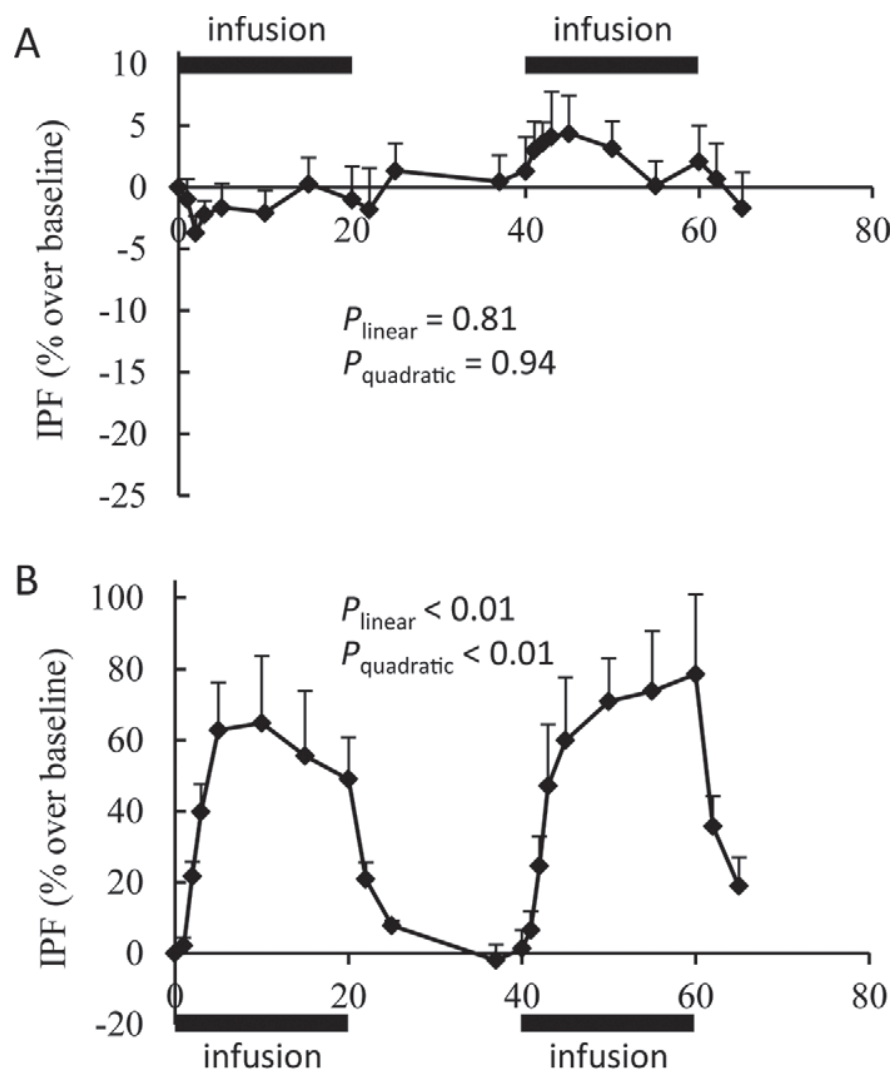

Time (min)

Figure 1. Time course of iliac plasma flows (IPF) as a percentage of the 0 -min value during arterial saline (A) and adenosine (B) infusions. Shaded bars indicate the first and second infusion periods. $P$-values indicate linear and quadratic effects of time during the infusion periods. period (average of values at 24, 27, and $30 \mathrm{~min}$ of $\mathrm{PAH}$ infusion). For those time-course curves where IPF did not return to the first baseline by $70 \mathrm{~min}$ of $\mathrm{PAH}$ infusion, changes in IPF during the second, 20-min, treatment period were also calculated relative to the value at 70 min. Changes in IPF in the 74-min inhibitor + glucose protocol were calculated relative to the average of values at 43 and 46 min of PAH infusion (13 and 16 min of inhibitor infusion). For each treatment, relative IPF values $\left(\mathrm{Y}_{\mathrm{ijk}}\right)$ were subjected to ANOVA using PROC MIXED of SAS (version 9; SAS Institute Inc., Cary, NC) according to

$\mathrm{Y}_{\mathrm{ijk}}=\mu+$ time $_{\mathrm{i}}+\operatorname{cow}_{\mathrm{j}}+\operatorname{rep}_{\mathrm{k}}+$ time $\times \operatorname{cow}_{\mathrm{ij}}+\varepsilon_{\mathrm{ijk}}$,

where $\mu=$ overall mean, time $_{i}=$ repeated time effect ( $\mathrm{i}=1$ to 10 or 21 for values normalized to the first or second baselines, respectively), $\operatorname{cow}_{\mathrm{j}}=\operatorname{cow} \operatorname{effect}(\mathrm{j}=$ 1 to 4$),$ rep $_{\mathrm{k}}=$ replication effect $(\mathrm{k}=1$ to 2$)$, and $\varepsilon_{\mathrm{ijk}}$ $=$ experimental error. Covariance in repeated measures on the same subject was accommodated with a firstorder, autoregressive structure. Linear and quadratic effects of time within each 20-min infusion period were estimated using coefficients calculated in PROC IML of SAS (SAS Institute Inc.). Significance of contrasts was declared at $P \leq 0.05$ and trends at $0.05<P \leq 0.10$.

\section{RESULTS}

Over the $12 \mathrm{~d}$ of the experiment, the cows consumed $17.7 \pm 1.1(\mathrm{SE}) \mathrm{kg} / \mathrm{d}$ of $\mathrm{DM}$, and produced $31.9 \pm 1.4$ $\mathrm{kg} / \mathrm{d}$ of milk containing $4.17 \pm 0.09 \%$ fat, $2.71 \pm 0.16 \%$ protein, and $4.87 \pm 0.04 \%$ lactose. According to NRC (2001) equations for $\mathrm{NE}_{\mathrm{L}}$ requirements, cows were in an $\mathrm{NE}_{\mathrm{L}}$ balance of $-2.0 \mathrm{Mcal} / \mathrm{d}$.

\section{Saline and Adenosine Infusions}

Infusion of hypertonic solutions has been shown to decrease vascular resistance in contracting muscles (Mellander and Lundvall, 1971). To test the possibility that effects of nutrient infusion were due to changes in osmolality, $0.38 \mathrm{~g} / \mathrm{min}$ of $\mathrm{NaCl}$ was infused into the external iliac artery. Iliac plasma flow was not significantly affected throughout the 95-min infusion protocol $(P=0.33)$ and the hypertonic $\mathrm{NaCl}$ did not cause a linear or quadratic change in IPF during infusion $(P>$ 0.81; Figure 1; Table 1). The lack of response to $\mathrm{NaCl}$ indicates that tonicity of the milk precursor solutions would not affect IPF in our experiment.

Adenosine is a potent vasodilator in many tissues of the body (Haddy and Scott, 1968) and the mammary glands are no exception. Because Prosser et al. (1996) demonstrated a 250\% increase in $\mathrm{MBF}$ within 15 min 

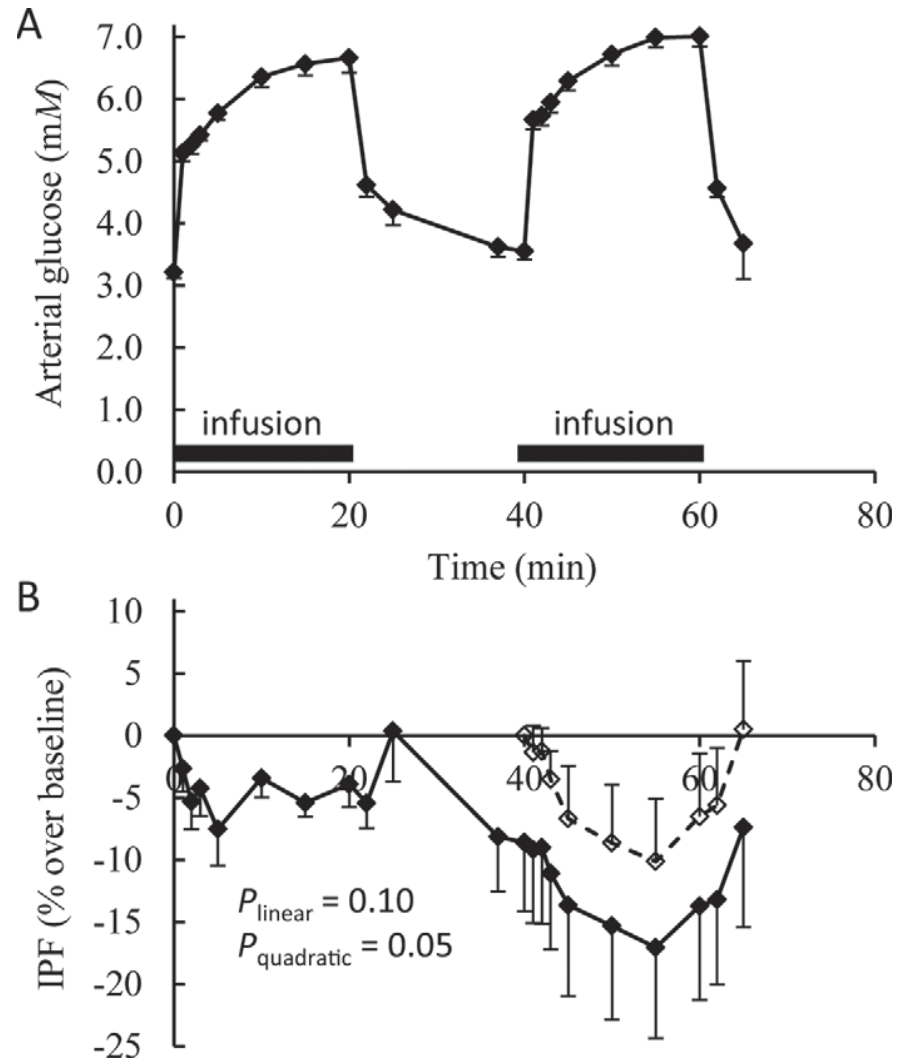

Figure 2. Time course of close arterial glucose concentrations (A) and iliac plasma flows (IPF) as a percentage of the 0- (solid line) and 40-min (dashed line) values (B) during arterial glucose infusion. Shaded bars indicate the first and second infusion periods. $P$-values indicate linear and quadratic effects of time during the infusion periods.

of adenosine infusion into the external pudendal artery of goats, we chose adenosine as a positive control to test the validity of measuring minute-to-minute blood flow changes by arteriovenous dilution of PAH with an automated venous sampling technique. Both linear and quadratic effects of time on IPF were detected during adenosine infusion $(P<0.01$; Table 1$)$ but the quadratic effect was most apparent (Figure 1), where the majority of the $73 \%$ increase in IPF occurred within the first 5 min of infusion. Thereafter, during adenosine infusion, IPF remained elevated. Furthermore, IPF returned to baseline values by the beginning of the second infusion period. These results indicate that the method for assessment of acute perturbations in IPF was adequate, and that the time-dependent response to constant delivery of a vasodilator is quadratic.

\section{Milk Precursor Infusions}

Infusion of glucose at $2.2 \mathrm{~g} / \mathrm{min}$ caused close arterial concentrations of glucose to increase from an average of $3.2 \mathrm{~m} M$ to a peak of $6.7 \mathrm{mM}$ in the first infusion period and to $7.0 \mathrm{mM}$ in the second (Figure 2). Concentrations returned to $11 \%$ above baseline in the 20 -min washout period between infusions. During glucose infusion, IPF decreased by $9 \%$ in a quadratic manner $(P=0.05$; Table 1 ), most rapidly in the first 5 min (Figure 2). Although IPF was depressed at the beginning of the second infusion of glucose, the infusion still caused a further decline in IPF. Iliac plasma flow increased upon cessation of both glucose infusions. The quadratic pattern of the IPF response to glucose is consistent with lower vasodilator release into the mammary vasculature.

Close arterial $\alpha$-amino- $\mathrm{N}$ concentrations were $130 \%$ greater than baseline values during the 20-min infusion of $2.11 \mathrm{~g} / \mathrm{min}$ of AA (Figure 3) and returned to baseline values within 20 min of cessation of infusion. In contrast to the rapid and sustained decrease in IPF during glucose infusion, IPF increased linearly by $9 \%$ throughout the AA infusions $(P=0.01$; Table 1$)$.

Infusion of $0.87 \mathrm{~g} / \mathrm{min}$ of TAG caused close arterial TAG concentrations to increase from 50 to $290 \mu M$ and NEFA concentrations to increase from 140 to $240 \mu M$
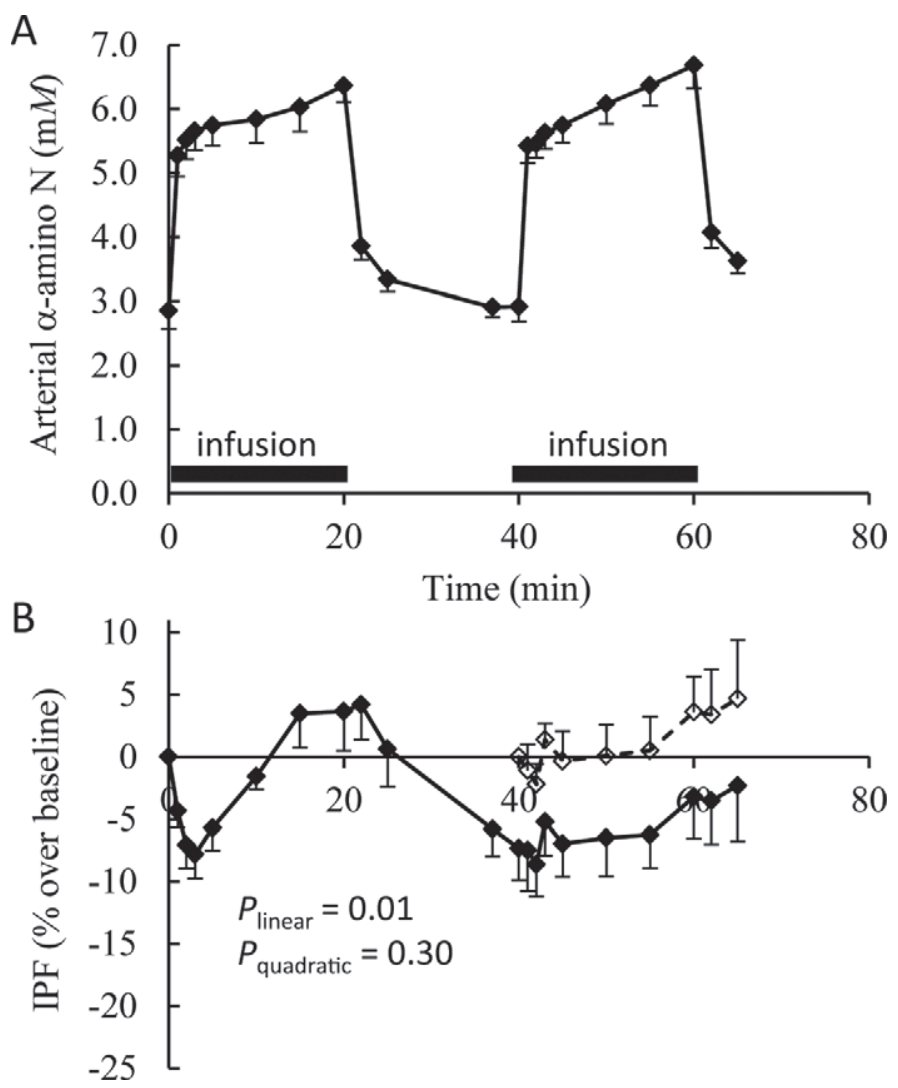

Figure 3. Time course of close arterial $\alpha$-amino $N$ concentrations (A) and iliac plasma flows (IPF) as a percentage of the 0- (solid line) and 40-min (dashed line) values (B) during arterial amino acid infusion. Shaded bars indicate the first and second infusion periods. $P$-values indicate linear and quadratic effects of time during the infusion periods. 
A
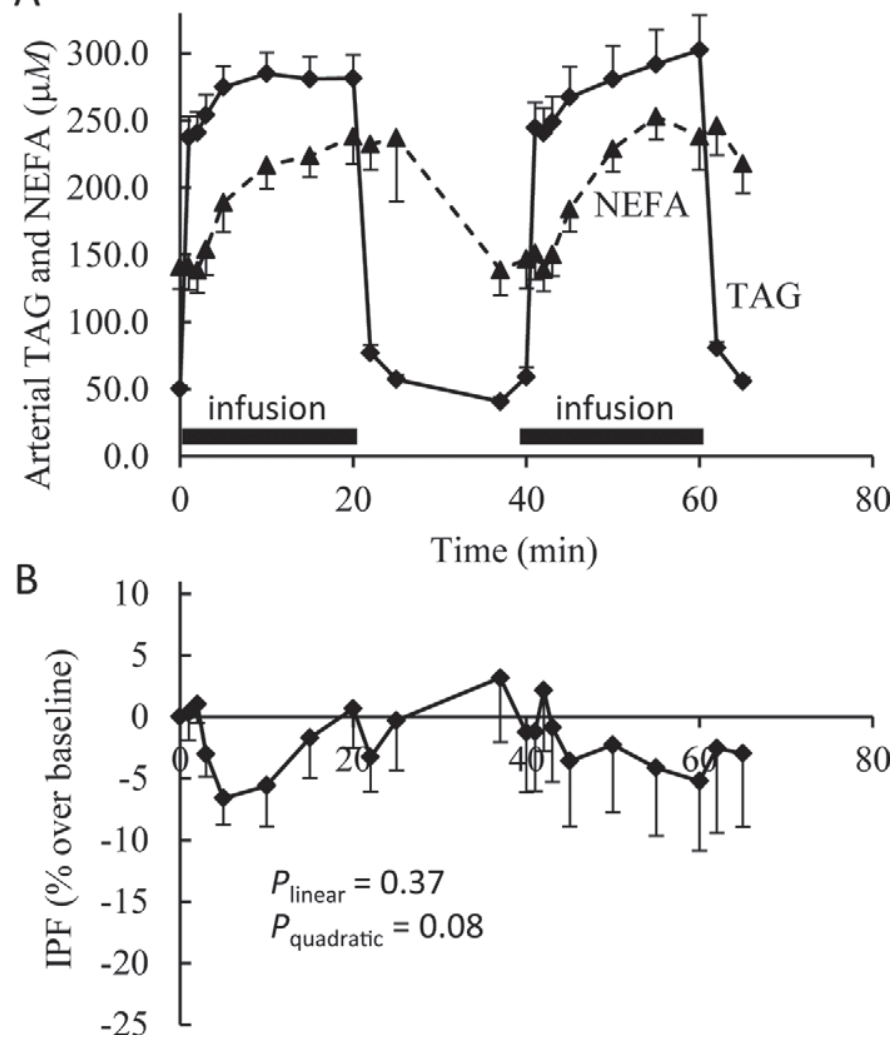

Figure 4. Time course of close arterial triacylglycerol (TAG) and NEFA concentrations (A) and iliac plasma flows (IPF) as a percentage of the 0-min value (B) during arterial TAG infusion. Shaded bars indicate the first and second infusion periods. $P$-values indicate linear and quadratic effects of time during the infusion periods.

(Figure 4). The large increase in circulating NEFA indicates that the infused TAG were extensively hydrolyzed by lipoprotein lipase. Upon cessation of TAG infusion, concentrations of both TAG and NEFA returned to baseline levels. We detected a tendency $(P=0.08)$ for a quadratic response in IPF to TAG infusion due to a rapid $8 \%$ decrease in IPF during the first 5 min of the first infusion period, followed by a return to baseline IPF while TAG infusion was still ongoing. The pattern was not repeated during the second infusion period. Thus, TAG at the same ATP equivalent as glucose did not elicit the same IPF response.

Close arterial insulin concentrations increased from 22 to $830 \mathrm{p} M$ during the first infusion of $20 \mu \mathrm{g} / \mathrm{min}$ insulin, and from 41 to 1,068 $\mathrm{p} M$ during the second infusion (Figure 5). Plasma glucose declined from 2.7 to $2.0 \mathrm{mM}$ by $37 \mathrm{~min}$ of the experiment and remained at $2.0 \mathrm{~m} M$ thereafter. We observed no effect on IPF during either of the insulin infusion periods, whereas IPF declined $10 \%$ between the first and second periods.

\section{Infusions of Blood Flow Inhibitors}

Indomethacin caused a transient 5\% increase in IPF during the first 2 min of infusion (Figure $6 \mathrm{~A}$ ), and then a rapid $30 \%$ decrease in IPF over the next 5 min $(P$ $<0.01$; Table 1), in both infusion periods. The IPF remained low throughout indomethacin infusion but returned to baseline within 6 min of termination. When glucose was infused at $2.2 \mathrm{~g} / \mathrm{min}$ during indomethacin treatment, we detected a quadratic increase in IPF to $9 \%$ above baseline that was maintained throughout (Figure 6B). This increase in IPF is in contrast to the glucose-mediated depression of IPF observed without indomethacin (Figure 2).

Infusion of L-NAME caused a linear decrease in IPF without a return to baseline between infusion periods (Figure 6C). This pattern indicates that NO synthase is required to maintain MBF but L-NAME exhibits a long residence time within the circulation. Glucose did not affect IPF in the presence of L-NAME (Figure 6D).

Glibenclamide did not affect IPF in either of the 2 infusion periods (Figure 6E). During glibenclamide treatment, glucose infusion did not elicit a decrease in IPF $(P>0.18$; Figure $6 \mathrm{~F})$. However, IPF increased $(P$ $<0.01$ ) when glucose infusion ceased (Figure $6 \mathrm{~F}$ ) in the same manner as observed without glibenclamide (Figure 2).

\section{DISCUSSION}

\section{MBF Is Locally Regulated by a Feedback Mechanism}

Previous studies of nutritional perturbation of MBF (Cant et al., 1993, 2002; Bequette et al., 2000) have been interpreted as showing that nutrient concentrations in blood supplying the mammary glands can influence the rate of blood flow to the glands (Cant and McBride, 1995; Cherepanov et al., 2000; Cant et al., 2003). Our current results show that these nutrientmediated changes occur within $5 \mathrm{~min}$. Changes in blood flow could represent nutritive flow through capillaries under the control of local vasodilatory mechanisms, or nonnutritive flow through arteriovenous shunts as part of the autonomic nervous control of systemic arterial pressure. Although some evidence suggests that a portion of MBF is nonnutritive (Prosser et al., 1996), the extent to which MBF is modulated to maintain arterial pressure and blood flow to other organs of the body remains unknown. Intravenous infusion of hypertonic glucose solutions may induce autonomic regulation of arterial blood pressure (Mostert et al., 1971) but we observed no effect of hypertonic saline on IPF. Thus, it is presumed for the following discussion that short-term changes in IPF in response to arterial nutrient infusions 
A
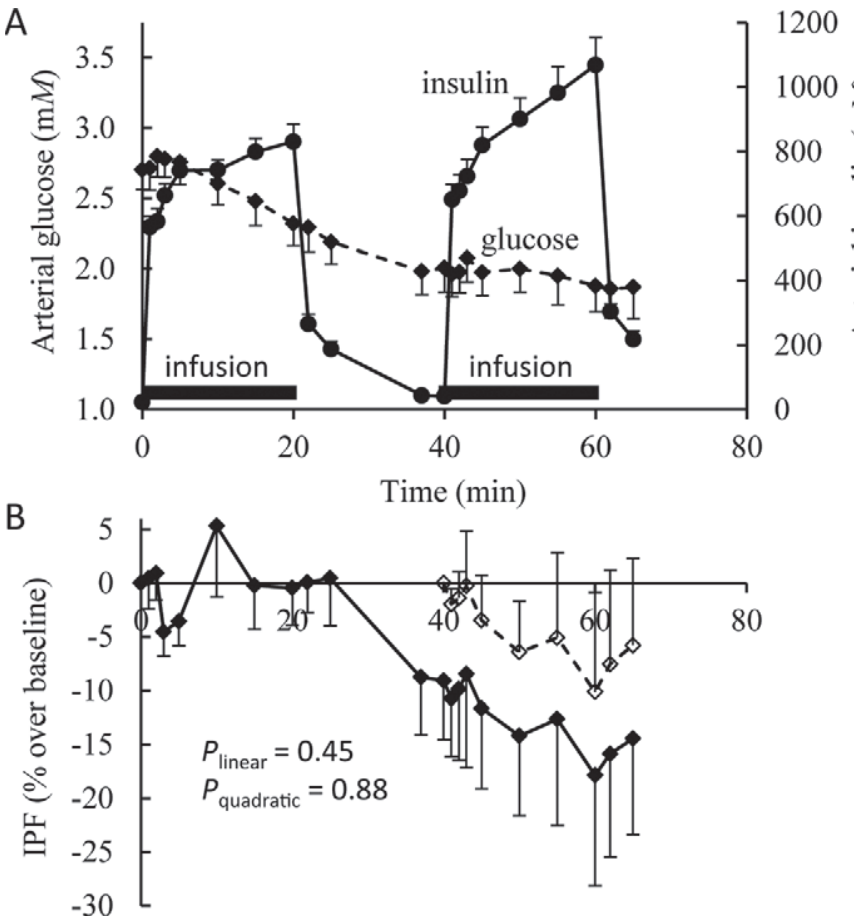

Figure 5. Time course of close arterial insulin and glucose concentrations (A) and iliac plasma flows (IPF) as a percentage of the 0 - (solid line) and 40-min (dashed line) values (B) during arterial insulin infusion. Shaded bars indicate the first and second infusion periods. $P$-values indicate linear and quadratic effects of time during the infusion periods.

were indicative of local vasodilatory mechanisms in the mammary glands.

Both feedforward and feedback mechanisms have been proposed to explain the link between metabolic activity of a tissue and its rate of blood flow (Deussen et al., 2012). Feedforward mechanisms postulate that increased intracellular catabolism of nutrients to $\mathrm{CO}_{2}$ and $\mathrm{H}_{2} \mathrm{O}$ is associated with a higher level of work in the tissue; that is, ATP expenditure. A greater nutrient supply is required for this work and, to provide these additional nutrients, blood flow is increased by vasodilatory end products of catabolism (vasodilatory compounds; VDC) such as $\mathrm{CO}_{2}, \mathrm{H}^{+}$, and $\mathrm{H}_{2} \mathrm{O}_{2}$. This mechanism presumes that nutrients are catabolized only when the demand for ATP arises, and not in relation to nutrient supply; otherwise, an elevated nutrient supply would increase blood flow via VDC. This higher blood flow would increase nutrient supply and catabolism further, thereby increasing blood flow again. Such an escalation is prevented by energetic regulation of catabolism, including the inhibition of glycolysis by ATP (Depré et al., 1998) and inhibition of fatty acid and glucose oxidation by citrate (Hue and Taegtmeyer, 2009). Thus, for a feedforward mechanism to work properly, catabolism and the resultant hyperemia only occur when the inhibitory effects of ATP and citrate are lifted as a consequence of ATP expenditure.

Feedforward mechanisms of blood flow regulation depend exclusively on a change in ATP expenditure to mediate a change in blood flow. Feedback mechanisms, on the other hand, postulate that vasodilators such as adenosine are released into the interstitium in proportion to the intracellular ADP:ATP ratio so that a change in either ATP utilization or production causes blood flow to change. If ATP expenditure increases, ADP production and adenosine release are stimulated and blood flow increases, whereas if nutrient catabolism increases, ADP is depleted and adenosine release declines, along with blood flow.

Of the 3 milk precursors tested, glucose decreased IPF, TAG tended to decrease IPF, and AA increased IPF. Each precursor, when taken up into the mammary epithelial cell, can be used either for anabolic production of milk lactose, fat, or protein, which consumes ATP, or for catabolism to generate ATP. A feedforward mechanism of energetic blood flow regulation cannot account for the $9 \%$ decrease in IPF observed during glucose infusion. The feedforward mechanism requires a decrease in VDC release to elicit a decrease in blood flow, and neither an increase in lactose synthesis nor an increase in glucose catabolism would decrease VDC release. However, a feedback mechanism would result in lower blood flow if the glucose were catabolized to generate ATP and adenosine release consequently declined. Because IPF decreased, the glucose results support existence of a feedback control mechanism in the mammary glands that is stronger than a feedforward effect.

During insulin infusion, glucose concentrations decreased to $2.0 \mathrm{~m} M$, which, to remain consistent with responses to glucose infusion, should have increased IPF. However, IPF did not increase, suggesting an opposing effect of insulin. Linzell (1967) observed a decrease in MBF and milk yield concurrent with decreased plasma glucose concentrations $1 \mathrm{~h}$ after insulin injection into goats. Anabolic effects of insulin on adipose and muscle tissues may have caused a diversion of cardiac output into these other tissues. Linzell (1967) also noted that MBF did not decrease in all goats in response to insulin. Similarly, we found a large variation in IPF during insulin infusion (Figure 5), indicating inconsistent responses between cows and making conclusions difficult.

Infusion of long-chain FA as TAG only tended to decrease IPF in a quadratic manner, suggesting that ATP balance was affected less by TAG than by glucose. Long-chain FA are not oxidized to any great extent in the lactating mammary gland (Rudolph et al., 2003) but they inhibit fat synthesis from acetate, which decreases ATP utilization, and stimulate lactose synthesis 
A

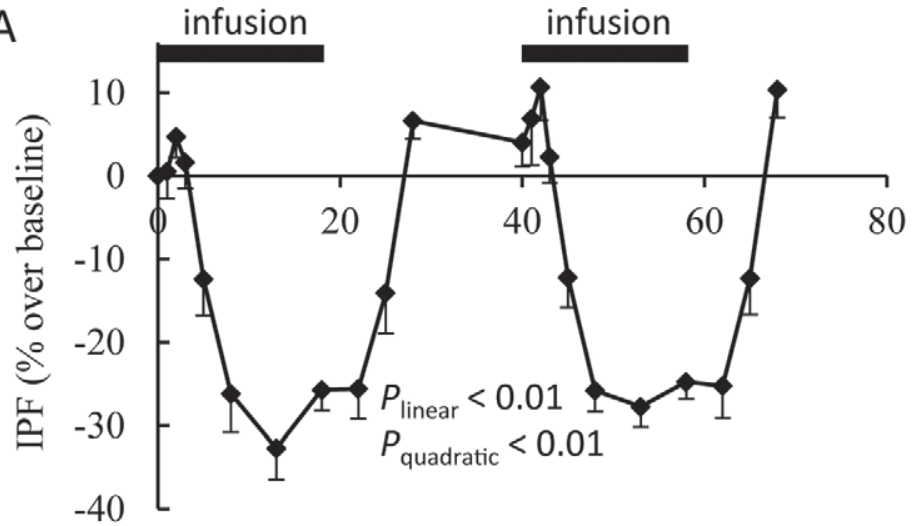

B

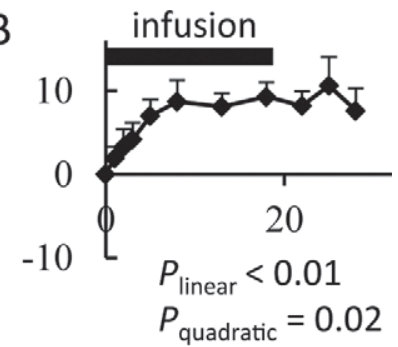

C

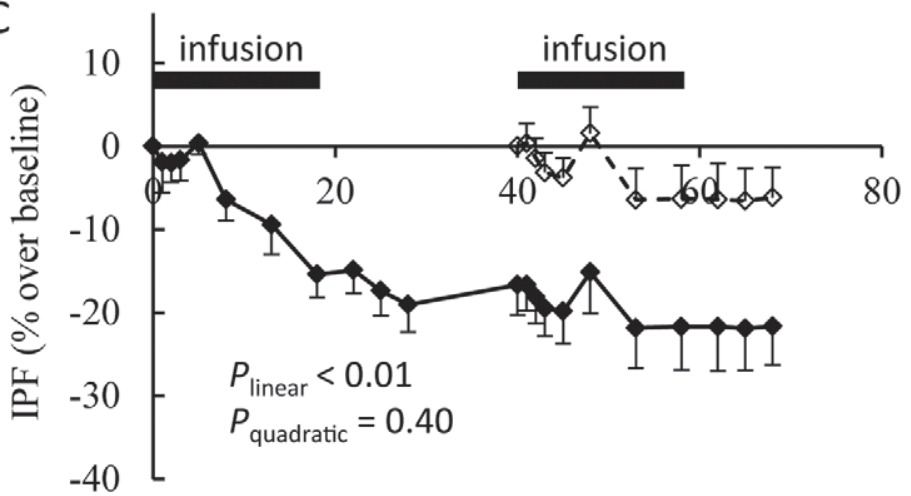

D

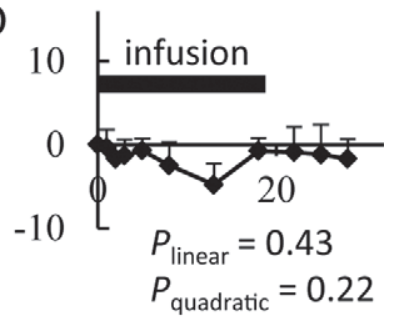

$E$

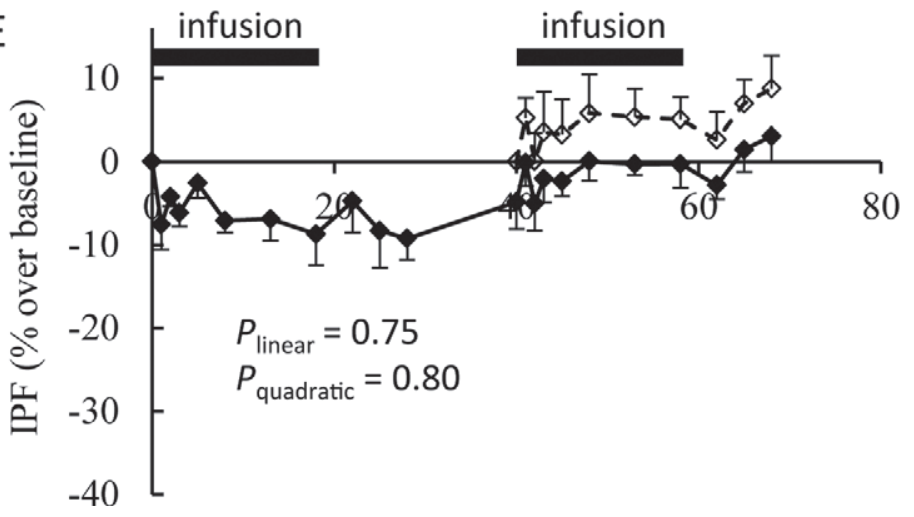

$\mathrm{F}$

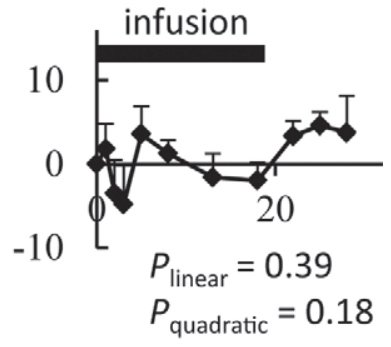

Figure 6. Time course of iliac plasma flows (IPF) as a percentage of the 0- (solid line) and 40-min (dashed line) values during arterial infusion of indomethacin (A), glucose during indomethacin (B), $\mathrm{N}_{\omega}$-nitro-L-arginine methyl ester hydrochloride (L-NAME; C), glucose during L-NAME $(\mathrm{D})$, glibenclamide $(\mathrm{E})$, and glucose during glibenclamide $(\mathrm{F})$. Shaded bars indicate the first and second infusion periods. $P$-values indicate linear and quadratic effects of time during the infusion periods.

from glucose, which increases ATP utilization (Cant et al., 1993). The opposing effects on ATP utilization may account for the small, nonsignificant change in IPF.

The increase in IPF during AA infusion suggests that mammary ATP utilization was stimulated. Amino acids activate mammary protein synthesis (Bequette et al., 2001), even within minutes of administration (Burgos et al., 2010), and protein synthesis consumes a substantial proportion of the mammary ATP use (Hanigan et al.,
2009). Although AA and glucose were infused to supply identical ATP yields when completely catabolized, the difference in IPF responses suggests that glucose was catabolized to a greater extent than AA. Stimulation of ATP utilization by AA could increase IPF by both feedforward and feedback mechanisms.

Hemodynamic responses to TAG and AA do not allow us to distinguish feedforward from feedback regulation of IPF. However, the response to glucose was a 
decrease in IPF, which can only be explained by a feedback mechanism. Acetate might have been a candidate to test the existence of feedback regulation because it is oxidized heavily in the mammary epithelium, but we have been unable to detect an effect of short-term, arterial acetate infusion on mammary ATP balance (Maas et al., 1995; Purdie et al., 2008). Similarly, glucose supplementation of mammary epithelial cells in vitro increased intracellular ATP concentrations, whereas acetate supplementation did not (Appuhamy et al., 2014).

\section{Nitric Oxide, But Not $\mathrm{PGI}_{2}$, Mediates the Glucose-Induced Decrease in Mammary Blood Flow}

The mechanisms by which blood flow to a tissue is locally regulated to match the metabolic rate of the tissue have not been fully elucidated. However, it is known that $\mathrm{PGI}_{2}$ and $\mathrm{NO}$ produced in the endothelium can play an important role. In skeletal and cardiac muscle, decreased partial pressure of $\mathrm{O}_{2}$ and elevated $\mathrm{H}_{2} \mathrm{O}_{2}$ as a result of oxidative metabolism activate endothelial $\mathrm{PGI}_{2}$ synthesis (Thengchaisri and Kuo, 2003; Deussen et al., 2012) and $\mathrm{PGI}_{2}$ relaxes vascular smooth muscle in a cyclic AMP-dependent manner (Hellsten et al., 2012). Thus, $\mathrm{PGI}_{2}$ is a mediator of the feedforward link between metabolic activity and blood flow. Muscular catabolism also produces the $\mathrm{VDC} \mathrm{CO}_{2}$ and $\mathrm{H}^{+}$, which activate endothelial NO synthesis (Deussen et al., 2012), as does adenosine (Hein and Kuo, 1999). As a mediator of both feedforward and feedback loops, NO acts through cyclic GMP to relax vascular smooth muscle (Hellsten et al., 2012). Adenosine and the VDC from oxidative metabolism can also cause membrane hyperpolarization and relaxation of vascular smooth muscle independently of the endothelium via $K_{\text {ATP }}$ and $\mathrm{K}_{\mathrm{V}}$ channels on the smooth muscle surface (Deussen et al., 2012).

To explore which of these vasodilatory systems are involved in the glucose-induced decrease in MBF, we infused inhibitors of $\mathrm{K}_{\text {ATP }}$ channels (glibenclamide), NO synthase (L-NAME), and COX (indomethacin), with and without glucose, into the mammary arterial supply. Inhibition of $\mathrm{K}_{\mathrm{ATP}}$ channels with glibenclamide had no effect on IPF. Although a decrease in IPF was not detected at the onset of glucose infusion in the presence of glibenclamide, an increase in IPF was detected upon cessation of glucose infusion, suggesting that the glucose response was not abolished and, therefore, does not involve $\mathrm{K}_{\mathrm{ATP}}$ channels.

Indomethacin depresses skeletal muscle blood flow by inhibiting $\mathrm{PGI}_{2}$ synthesis in the endothelium and by inhibiting mitochondrial respiration in skeletal muscle (Boushel et al., 2012). When we infused indomethacin into the mammary circulation, we observed a $35 \%$ reduction in IPF, in agreement with a $40 \%$ decrease in MBF observed in goats (Nielsen et al., 1995a), which suggests a role for $\mathrm{PGI}_{2}$ and the feedforward effects of VDC from oxidative metabolism in maintaining MBF. However, feedback regulation through adenosine and NO is implicated when glucose was included with indomethacin and IPF increased instead of decreasing as it had without indomethacin. If indomethacin inhibits mitochondrial respiration in the mammary glands as in skeletal muscle, then the supplemental glucose would not be able to increase ADP utilization or production of VDC from oxidative metabolism (Figure 7). Only anabolic utilization of glucose would be possible, causing production of ADP and adenosine, which relaxes vascular smooth muscle via endothelial NO synthesis (Hein and Kuo, 1999; Hellsten et al., 2012). Because adenosine and NO synthesis are not inhibited during indomethacin infusion, we can infer that they contributed to the glucose response. Furthermore, this role of the feedback regulator of blood flow (adenosine) is consistent with the conclusion from glucose infusion, without inhibitors, that a feedback mechanism was involved.

When IPF was depressed with the NO synthase inhibitor L-NAME so that only $\mathrm{PGI}_{2}$ was operative in the endothelium, glucose had no effect on blood flow, indicating that $\mathrm{PGI}_{2}$ was not involved in the glucoseinduced decrease in $\mathrm{MBF}$. Because $\mathrm{PGI}_{2}$ mediates the feedforward effects of energy metabolism on blood flow (Thengchaisri and Kuo, 2003; Deussen et al., 2012), its lack of participation is consistent with a feedback response to glucose. The proposed feedback response to glucose occurs through catabolic production of ATP that decreases adenosine release into the interstitium and thereby deactivates endothelial NO synthase. If the L-NAME maximally inhibited NO synthase, then the glucose infusion would not be able to further deactivate it and IPF would not decrease. The lack of an IPF response to glucose during L-NAME infusion is consistent with this feedback role of $\mathrm{NO}$, and not $\mathrm{PGI}_{2}$, in nutrient-induced mammary hyperemia.

\section{Link Between MBF and Metabolic Activity}

Based on the patterns of IPF observed in our experiments, we propose the model in Figure 7 to link metabolic activity in the mammary glands with $\mathrm{MBF}$. Nutrients taken into the mammary epithelia from blood can be used for both anabolic and catabolic purposes, thereby using and producing ATP, respectively. The release of adenosine into the interstitium, where it activates endothelial NO synthesis and a consequent vascular relaxation, is directly related to intracellular 


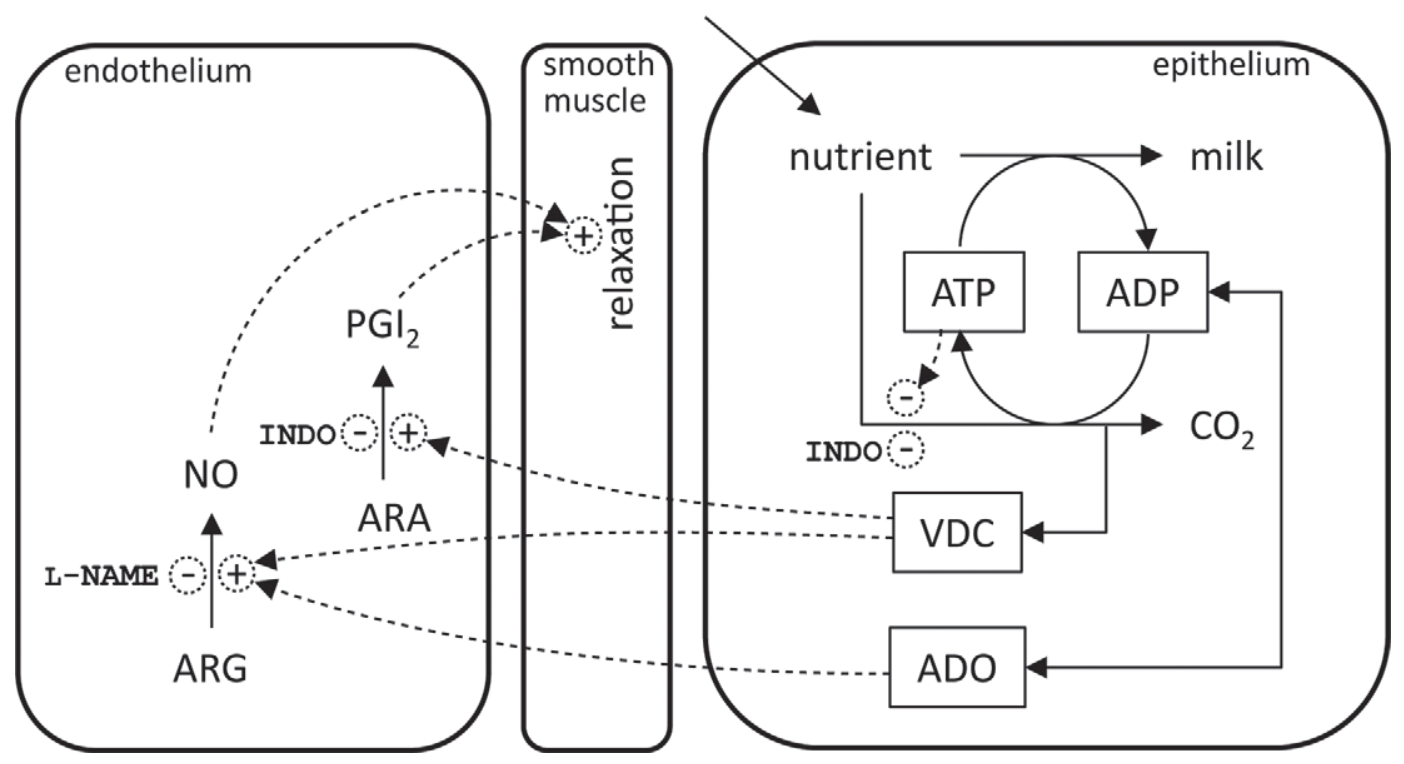

Figure 7. Proposed model of link between metabolic activity of mammary tissue and blood flow rate. Solid arrows represent mass flux and dashed arrows represent effector mechanisms; + and - represent activation and inhibition, respectively. ADO $=$ adenosine, ARA $=$ arachidonic acid, $\mathrm{ARG}=$ arginine, $\mathrm{INDO}=$ indomethacin, $\mathrm{L}-\mathrm{NAME}=\mathrm{N}_{\omega}$-nitro-L-arginine methyl ester hydrochloride, $\mathrm{NO}=$ nitric oxide, $\mathrm{PGI}{ }_{2}=$ prostacyclin, $\mathrm{VDC}=$ vasodilatory compounds.

ADP concentration. This relationship completes a feedback loop where, if ATP production exceeds utilization, adenosine release declines and MBF decreases, and vice versa.

Although L-NAME infusion showed that COX was not involved in the MBF response to glucose, we cannot rule out a feedforward mechanism of MBF control via COX because indomethacin decreased IPF in our study and others (Nielsen et al., 1995a). Furthermore, stimulation of mammary activity with growth hormone increases $\mathrm{PGI}_{2}$ synthesis and MBF (Christensen et al., 1989; Nielsen et al., 2004), and a vasodilatory effect of $\mathrm{CO}_{2}$ in the mammary vasculature accounts for approximately one-third of the variation in MBF throughout lactation (Nielsen et al., 1995b). In the feedforward scenario, VDC are released into the interstitium as a result of oxidative catabolism, activating $\mathrm{PGI}_{2}$ and NO synthesis in the endothelium and causing vascular relaxation.

The IPF responses to glucose infusion show that the feedback mechanism of energetic MBF control is dominant over the feedforward mechanism. We conclude that feedback control should be the mechanism described in simulation models to account for variation in arterial supply of nutrients to the mammary glands and their utilization for milk synthesis.

\section{ACKNOWLEDGMENTS}

We thank Jodi Calberry, Sarah Armstrong, Andrea Tschudi, Jeff Keunen, Lotje Kouwenberg, and Sue Sin- clair (University of Guelph, Guelph, ON, Canada) for their skillful technical assistance. Financial support for this work was provided by NSERC Canada (Ottawa, ON, Canada) and the Ontario Ministry of Agriculture and Food (Guelph, ON, Canada). Norm Purdie was in receipt of a Dairy Research Development Corporation postgraduate award. Torben Madsen was in receipt of a postgraduate award from the Faculty of Life Sciences, Copenhagen University, Denmark.

\section{REFERENCES}

AOAC International. 1996. Official Methods of Analysis. 16th ed. AOAC International, Arlington, VA.

Appuhamy, J. A. D. R. N., W. A. Nayananjalie, E. M. England, D. E. Gerrard, R. M. Akers, and M. D. Hanigan. 2014. Effects of AMP-activated protein kinase (AMPK) signaling and essential amino acids on mammalian target of rapamycin (mTOR) signaling and protein synthesis rates in mammary cells. J. Dairy Sci. $97: 419-429$.

Bequette, B. J., M. D. Hanigan, A. G. Calder, C. K. Reynolds, G. E. Lobley, and J. C. MacRae. 2000. Amino acid exchange by the mammary gland of lactating goats when histidine limits milk production. J. Dairy Sci. 83:765-775.

Bequette, B. J., C. E. Kyle, L. A. Crompton, V. Buchan, and M. D. Hanigan. 2001. Insulin regulates milk production and mammary gland and hind-leg amino acid fluxes and blood flow in lactating goats. J. Dairy Sci. 84:241-255.

Boushel, R., T. Fuentes, Y. Hellsten, and B. Saltin. 2012. Opposing effects of nitric oxide and prostaglandin inhibition on muscle mitochondrial $\mathrm{V}_{\mathrm{O} 2}$ during exercise. Am. J. Physiol. 303:R94-R100.

Burgos, S. A., M. Dai, and J. P. Cant. 2010. Nutrient availability and lactogenic hormones regulate mammary protein synthesis through the mammalian target of rapamycin signaling pathway. J. Dairy Sci. 93:153-161.

Cant, J. P., R. Berthiaume, H. Lapierre, P. H. Luimes, B. W. McBride, and D. Pacheco. 2003. Responses of the bovine mammary glands 
to absorptive supply of single amino acids. Can. J. Anim. Sci. 83:341-355.

Cant, J. P., E. J. DePeters, and R. L. Baldwin. 1993. Mammary uptake of energy metabolites in dairy cows fed fat and its relationship to milk protein depression. J. Dairy Sci. 76:2254-2265.

Cant, J. P., and B. W. McBride. 1995. Mathematical analysis of the relationship between blood flow and uptake of nutrients in the mammary glands of a lactating cow. J. Dairy Res. 62:405-422.

Cant, J. P., D. R. Trout, F. Qiao, and B. W. McBride. 2001. Milk composition responses to unilateral arterial infusion of complete and histidine-lacking amino acid mixtures to the mammary glands of cows. J. Dairy Sci. 84:1192-1200.

Cant, J. P., D. R. Trout, F. Qiao, and N. G. Purdie. 2002. Milk synthetic response of the bovine mammary gland to an increase in the local concentration of arterial glucose. J. Dairy Sci. 85:494-503.

Cherepanov, G. G., A. Danfaer, and J. P. Cant. 2000. Simulation analysis of substrate utilization in the mammary gland of lactating cows. J. Dairy Res. 67:171-188.

Christensen, K., M. O. Nielsen, and N. Jarløv. 1989. The excretion of prostacyclin (PGI2) in milk and its possible role as a dilator in the mammary gland of goats. Comp. Biochem. Physiol. 93A:477-481.

Depré, C., M. H. Rider, and L. Hue. 1998. Mechanisms of control of heart glycolysis. Eur. J. Biochem. 258:277-290.

Deussen, A., V. Ohanyan, A. Jannasch, L. Yin, and W. Chilian. 2012 Mechanisms of metabolic coronary flow regulation. J. Mol. Cell. Cardiol. 52:794-801.

Evans, P. C., F. M. Ffolliott-Powell, and J. E. Harding. 1993. A colorimetric assay for amino nitrogen in small volumes of blood: Reaction with $\beta$-naphthoquinone sulfonate. Anal. Biochem. 208:334337.

Gurevicius, J., M. R. Salem, A. A. Metwally, J. M. Silver, and G. J. Crystal. 1995. Contribution of nitric oxide to coronary vasodilation during hypercapnic acidosis. Am. J. Physiol. 268:H39-H47.

Haddy, F. J., J. Scott, M. Fleishmann, and D. Emanuel. 1958. Effect of change in flow rate upon renal vascular resistance. Am. J. Physiol. 195:111-119.

Haddy, F. J., and J. B. Scott. 1968. Metabolically linked vasoactive chemicals in local regulation of blood flow. Physiol. Rev. 48:688707.

Hambraeus, L. 1982. Nutritional aspects of milk proteins. Pages 289313 in Developments in Dairy Chemistry - 1: Proteins. P. F. Fox, ed. Applied Science Publishers, London, UK.

Hanigan, M. D., J. France, S. J. Mabjeesh, W. C. McNabb, and B. J Bequette. 2009. High rates of mammary tissue protein turnover in lactating goats are energetically costly. J. Nutr. 139:1118-1127.

Hein, T. W., and L. Kuo. 1999. cAMP-independent dilation of coronary arterioles to adenosine: Role of nitric oxide, $\mathrm{G}$ proteins, and $\mathrm{K}_{\text {ATP }}$ channels. Circ. Res. 85:634-642.

Hellsten, Y., M. Nyberg, L. G. Jensen, and S. P. Mortensen. 2012 Vasodilator interactions in skeletal muscle blood flow regulation. J. Physiol. 590:6297-6305.

Hue, L., and H. Taegtmeyer. 2009. The Randle cycle revisited: A new head for an old hat. Am. J. Physiol. Endocrinol. Metab. 297:E578-E591.

Jones, R. D., and R. M. Berne. 1964. Local regulation of blood flow in skeletal muscle. Circ. Res. 15:30-38.

Lacasse, P., V. C. Farr, S. R. Davis, and C. G. Prosser. 1996. Local secretion of nitric oxide and the control of mammary blood flow. J. Dairy Sci. 79:1369-1374.

Linzell, J. L. 1967. The effect of infusions of glucose, acetate and amino acids on hourly milk yield in fed, fasted and insulin-treated goats. J. Physiol. 190:347-357.
Linzell, J. L. 1974. Mammary blood flow and methods of identifying and measuring precursors of milk. Pages 143-225 in Lactation: A Comprehensive Treatise. Vol. 1. B. L. Larson and V. R. Smith, ed. Academic Press, New York, NY.

Maas, J. A., D. R. Trout, J. P. Cant, B. W. McBride, and D. P. Poppi. 1995. Method for close arterial infusion of the lactating mammary gland. Can. J. Anim. Sci. 75:345-349.

Mellander, S., and J. Lundvall. 1971. Role of tissue hyperosmolality in exercise hyperaemia. Circ. Res. 28(Suppl. 1):39-45.

Mostert, J. W., R. J. Trudnowski, J. L. Evers, G. H. Hobika, R. H. Moore, and G. P. Murphy. 1971. Cardiovascular responses to hypertonic glucose: An aspect of resuscitation studied in patients with chronic renal failure. Anaesthesia 26:334-347.

Nielsen, M. O., I. R. Fleet, K. Jakobsen, and R. B. Heap. 1995a. The local differential effect of prostacyclin, prostaglandin $\mathrm{E}_{2}$ and prostaglandin $\mathrm{F}_{2 \alpha}$ on mammary blood flow of lactating goats. J Endocrinol. 145:585-591

Nielsen, M. O., S. Nyborg, K. Jakobsen, I. R. Fleet, and J. Nørgaard. 2004. Mammary uptake and excretion of prostanoids in relation to mammary blood flow and milk yield during pregnancy-lactation and somatotropin treatment in dairy goats. Domest. Anim. Endocrinol. 27:345-362.

Nielsen, M. O., C. Schleisner, K. Jakobsen, and P. H. Andersen. 1995b. The effect of mammary $\mathrm{O}_{2}$ uptake, $\mathrm{CO}_{2}$ and $\mathrm{H}^{+}$production on mammary blood flow during pregnancy, lactation and somatotropin treatment in goats. Comp. Biochem. Physiol. 112A:591-599.

NRC. 2001. Nutrient Requirements of Dairy Cattle. 7th rev. ed. National Academies Press, Washington, DC.

Oguro, K., H. Hashimoto, and M. Nakashima. 1982. Pharmacological effects of several drugs on the myoepithelium and the vascular smooth muscle of the lactating mammary glands in goats. Arch. Int. Pharmacodyn. Ther. 256:108-122.

Prosser, C. G., S. R. Davis, V. C. Farr, and P. Lacasse. 1996. Regulation of blood flow in the mammary microvasculature. J. Dairy Sci. 79:1184-1197.

Purdie, N. G., D. R. Trout, D. P. Poppi, and J. P. Cant. 2008. Milk synthetic response of the bovine mammary gland to an increase in the local concentration of amino acids and acetate. J. Dairy Sci. $91: 218-228$

Rådegran, G., and Y. Hellsten. 2000. Adenosine and nitric oxide in exercise-induced human skeletal muscle vasodilatation. Acta Physiol. Scand. 168:575-591

Rådegran, G., and B. Saltin. 1998. Muscle blood flow at onset of dynamic exercise in humans. Am. J. Physiol. 274:H314-H322.

Rogers, P. A., G. M. Dick, J. D. Knudson, M. Focardi, I. N. Bratz, A. N. Swafford Jr., S. I. Saitoh, J. D. Tune, and W. M. Chilian. 2006. $\mathrm{H}_{2} \mathrm{O}_{2}$-induced redox-sensitive coronary vasodilation is mediated by 4 -aminopyridinesensitive $\mathrm{K}^{+}$channels. Am. J. Physiol. 291:H2473-H2482.

Rudolph, M. C., J. L. McManaman, L. Hunter, T. Phang, and M. C. Neville. 2003. Functional development of the mammary gland: Use of expression profiling and trajectory clustering to reveal changes in gene expression during pregnancy, lactation, and involution. J. Mammary Gland Biol. Neoplasia 8:287-307.

Scott, J. B., B. R. M. Daugherty Jr., J. M. Dabney, and F. J. Haddy. 1965. Role of chemical factors in regulation of flow through kidney, hindlimb and heart. Am. J. Physiol. 208:813-824.

Thengchaisri, N., and L. Kuo. 2003. Hydrogen peroxide induces endothelium-dependent and -independent coronary arteriolar dilation: Role of cyclooxygenase and potassium channels. Am. J. Physiol. Heart Circ. Physiol. 285:H2255-H2263. 